\title{
Perceptions of Social Justice and Attitudes toward Inclusive Education among Pre-Service Teachers in the USA: A Brief Report of an Exploratory Study
}

\author{
Eric Shyman* and Jessica Scher Lisa \\ Associate Professor of Child Study, St Joseph's College, USA
}

Submission: July 03, 2017; Published: July 17, 2017

*Corresponding author: Eric Shyman, Associate Professor of Child Study, St. Joseph's College, 155 W, Roe Blvd, Patchogue, NY 11772, USA, Tel: 631-687-1222; Email:eshyman@sjcny.edu

\begin{abstract}
With the signing of the Education for All initiative of 2000, as well as the United Nations Convention on the Rights of Persons with Disabilities of 2007 bolstering the call for inclusive education globally, research investigating attitudes toward inclusive education among education professionals has become exigent. This article reports the findings of an exploratory study which examined the correlation between and predictive validity of the perceptions of social justice and attitudes toward inclusive education for individuals with disabilities among 96 preservice teachers at a school of education in the United States. Results suggested a significant positive correlation between affirmative perceptions of social justice and supportive attitudes toward inclusive education. Further, a hierarchical regression analysis revealed a small but significant level of predictive validity between perceived social justices on attitudes toward inclusive education. Implications and further directions for research are discussed.
\end{abstract}

\section{Introduction}

The movement toward inclusive education for individuals with intellectual and developmental disabilities is increasing steadily on a global level, as evidenced by the 21st century initiatives of Education for all as well as the UN Convention on Persons with Disabilities [1,2]. In order to ensure that the efforts toward more inclusive opportunities for individuals with intellectual and developmental disabilities is addressed with care and precision, increased attention in research must also be put forth in addition to policy and practice reforms. One area of potential research is the investigation of attitudes and perceptions of pre-service teachers, or teachers in training, toward inclusive education.

There are a number of means by which inclusive education is conceptualized in the literature, including time spent in the general education classroom and including students during times of academic strengths. While these pragmatic conceptions are common and sensible from a certain perspective, a potentially more important and socially relevant means is to conceptualize inclusive education in terms of social justice [1,3]. That is, including individuals with intellectual and developmental disabilities in general education classrooms with non-disabled peers is not just an educational policy reformation, but rather a social justice policy reformation implemented to fulfill an individual's social and civil rights.

The elusive nature of measuring perceptions of social justice creates numerous challenges for researchers, causing many to pursue other more attainable avenues. For this reason, research on social justice in education is sparse. However, one's sense of morality, especially in terms of perception of social justice, is an imperative factor in the effectiveness and the longevity of practicing teachers, especially those who work with marginalized groups of any kind [4,5]. Furthermore, while there are

some very valuable qualitative inquiries into the nature of social justice across many disciplines, systematic quantitative inquiries are much less available. One reason for this sparsity is the difficulty in conceptualizing and quantifying social justice in a meaningful way. For the purpose of this paper, social justice will be conceptualized as working to elucidate social practices of domination, privilege, and oppression in which inequities are not addressed through redistribution of wealth or resources, but through the requirement of unjust processes to be scrutinized and transformed at a practicable social level [6].

Inclusive education is another element of 21st century schooling that is apt to present conceptual and methodological 
challenges for research due to the multitude of definitions and practices available that have been constituted as "inclusive." Further, measuring individual attitudes toward inclusive education can also be challenging due to a paucity of available instrumentation. However, if a global move toward inclusive education is to be successful, deepening and widening the understanding of both pre-service and in-service teacher attitudes is imperative, as logic dictates that if there is a lack of support for inclusive education, there is likely to be a lack of willing teachers to develop and improve upon inclusive-based practices. The current study aims to investigate the following questions:

a. Do pre-service teachers display positive and supportive attitudes toward inclusive education?

b. Do pre-service teachers display an affirmative perception of social justice?

c. Is there a correlation between perceptions of social justice and attitudes toward inclusive education?

d. Can perception of social justice be used as a predictor for positive attitudes toward inclusive education?

\section{Method}

\section{Participants and setting}

A sample of 96 pre-service teachers from a college-based teacher training program in the United States was used. All participants were enrolled in a degree preparation program leading to state-based teacher certification in both general education and Students with Disabilities, yielding two total certifications. Participants were recruited via printed advertisement and personal request after the researchers obtained permission from the college's upper administration, school and department level administrators and chairpersons, as well as individual professors. The study also received full approval from the institution's Institutional Review Board. Participants ranged in age from 20-50 years old, with $85 \%$ identified as being in their 20's (age 20-29). Eighty-three percent of the participants were female; while $16 \%$ were male (1 participant did not identify gender). This demographic information is illustrated in Table 1.

Table 1: Demographic characteristics.

\begin{tabular}{|c|c|}
\hline Gender & \% \\
\hline Male & 16 \\
\hline Female & 83 \\
\hline Age & $\%$ \\
\hline $20-29$ & 85 \\
\hline $30-50$ & 15 \\
\hline
\end{tabular}

\section{Instrumentation}

Perceptions of social justice were measured using the Perception of Purpose subscale of the Eastern Teacher Disposition Index (ETDI) [7], which employs a Likert-type rating system of 1-6 (strongly disagree to strongly agree). This subscale consisted of 15 questions which mirrored concepts of morality and social justice as delineated in the extant literature $[4,5]$. The maximum score for this subscale is 90 , with higher ratings indicating a more affirmative perception of social justice. There is no established reliability score to date present in the literature. For the current sample, reliability analysis was calculated using Cronbach's alpha and determined as high $(\alpha=0.872)$. Attitudes toward and perceptions of inclusive education were measured by the Attitudes toward Inclusive Education Scale (ATIES) [8], a 16-item Likert-type scale from 1-6 (strongly disagree to strongly agree), with higher ratings indicating more positive attitudes. The maximum score for the ATIES is 96. Reliability for this scale has been established in the literature yielding Cronbach's alpha scores as high as $\alpha=0.88$ [8-10]. For the current sample, reliability analysis using Cronbach's alpha was calculated as high $(\alpha=0.83)$.

Table 2: Distribution results.

\begin{tabular}{|c|c|c|c|c|}
\hline & \multicolumn{4}{|c|}{ Frequency } \\
\hline & f & $\%$ & Range & Mode \\
\hline Attitudes toward Inclusive Education Scale (ATIES) & & & $29-85$ & 59 \\
\hline Low Support (16-42) & 9 & 9.6 & & \\
\hline Moderate Support (43-69) & 74 & 76.9 & & \\
\hline High Support (70-96) & 13 & 13.5 & & \\
\hline Eastern Teachers Disposition Index (ETDI) & & & $69-90$ & 90 \\
\hline 90 & 37 & 39.4 & & \\
\hline $80-89$ & 45 & 47.9 & & \\
\hline$<79$ & 12 & 14 & & \\
\hline
\end{tabular}

Results

\section{Do pre-service teachers display positive and supportive attitudes toward inclusive education?}

The participants' attitudes toward inclusive education was measured using the Attitudes toward Inclusive Education Scale
(ATIES), which is a 16-item scale employing a Likert-type rating system of 1 (strongly disagree) to 6 (strongly agree), with a maximum score of 96. Participant scores indicated a range of $29-85$, with a mode of 58 . Frequency distributions indicated that $9(9.6 \%)$ of the respondents indicated low support (16-42), 74 
(76.9\%) of the students indicated moderate support (43-69), and $13(13.5 \%)$ indicated high support.

\section{Do pre-service teachers display an affirmative perception of social justice?}

Respondents affirmative perception of social justice was measured by the Perception of Purpose subscale of the Eastern Teachers Disposition Index, which is a 15-item questionnaire with a maximum score of 90 . For the current sample, the range of scores was 69-90, with a mode of 90. Frequency distributions indicated that $37(39.4 \%)$ of respondents indicated a score of $90,45(47.9 \%)$ indicated a score of $80-89$, and $12(14 \%)$ of respondents indicated a score of less than 79 . Distribution results are illustrated in Table 2.

\section{Is there a correlation between perceptions of social justice and attitudes toward inclusive education?}

In order to begin to understand whether the concepts of social justice and attitudes toward inclusive education are related, Pearson correlations were run between the Perception of Purpose subscale of the ETDI and the ATIES score. Results

Table 4: Regression for attitudes toward inclusive education.

\begin{tabular}{|c|c|c|c|c|c|c|c|}
\hline Source & r2 & $\boldsymbol{\beta}$ & B & SS & df & MS & F \\
\hline $\begin{array}{c}\text { Perception of } \\
\text { Purpose }\end{array}$ & $0.047^{*}$ & 0.218 & 18.018 & 577.734 & 1 & 577.734 & 4.571 \\
\hline
\end{tabular}

SS: Sum of Squares, MS: Mean square, ${ }^{*} p<0.05$

\section{Discussion}

This exploratory study sought to investigate pre service teachers' affirmative perceptions of social justice and its connection to attitudes toward inclusive education. Overall, the pre service teachers in the sample indicated generally positive support for inclusive education, with the majority scoring in the moderate to high support range. This finding is similar to those reported in the extant literature [11-13]. Additionally, results indicated that the pre service teachers demonstrated generally affirmative perceptions of social justice. Because this area is not widely studied, it is unclear whether these results represent typical findings. Finally, statistical analyses indicated that there was a small but significant correlation and VAF for the Perception of Purpose score on the ATIES score, suggesting that it is possible that affirmative perceptions of social justice may predict positive attitudes toward inclusive education. These findings, too, lack precedent in the extant research.

As this study was exploratory in nature, there are a number of limitations that must be considered. First and foremost, the sample utilized was somewhat small, and comprised members of the same teacher preparation program. Additionally, there were a disproportionate number of females in the sample. Therefore, it is unclear whether these findings are generalizable or idiosyncratic to the particular program from which the participants were drawn. Second, because the instrumentation

\section{Limitations}

indicated that here was a small but significant correlation between the Perception of Purpose subscale score and ATIES

Table 3: Correlation between ETDI and ATIES scores.

\begin{tabular}{|c|c|c|}
\hline Measure & $\mathbf{1}$ & $\mathbf{2}$ \\
\hline 1-ETDI & 1 & $0.218^{*}$ \\
\hline 2-ATIES & $0.218^{*}$ & 1 \\
\hline${ }^{*} p<0.05$ &
\end{tabular}

\section{Can perception of social justice be used as a predictor for positive attitudes toward inclusive education?}

Because the Perception of Purpose score correlated at a small but significant level with the ATIES score, its potential as a predictor variable was investigated by running a hierarchical regression analysis. This statistic was used to determine the variance accounted for (VAF) by the Perception of Purpose score on the ATIES. Results of the hierarchical regression analysis indicated that Perception of Purpose subscale score significantly accounted for approximately 4-5\% ( $\mathrm{r} 2=0.047$; $\mathrm{p}<0.05)$ of the variance of ATIES. Results of the hierarchical regression analysis are summarized in Table 4. score $(\mathrm{r}=0.218 ; \mathrm{p}<0.05)$. Correlations are summarized in Table 3. possible to verify that the information provided represented accurate or stable indications of perceptions of either perception of social justice or attitudes toward inclusive education. Both measures, however, did attain high reliability scores within the sample itself.

\section{Suggestions for Future Research and Practical Applications}

As an exploratory study, the main purpose of conducting this research was to explore potential relationships between variables in order to inform decision making for more robust and comprehensive future studies. It is suggested that future research endeavors utilize larger and more heterogeneous samples that are better representative of more diverse populations geographically and programmatically. Further research would also benefit from the use of a more sophisticated questionnaire implementing multiple measures for each variable. A more sophisticated questionnaire would likely provide a more comprehensive representation of each variable, and potentially better capture the essential elements of each concept.

In terms of practical applications, while the findings of the study must still be carefully contextualized within its scope and limitations, the results indicated that social justice may be as important a component to the development of both teacher attitudes and teacher practices as are pedagogical methodology 
and content knowledge. As such, teacher programs can capitalize on such measures to assess whether and how concepts of social justice are addressed through coursework, and how support for inclusive educational practices can be infused within the whole of the teacher education program. Additionally, as measures become more reliable and sophisticated, teacher preparation programs can incorporate the use of periodic analyses that monitor potential change, growth, and development of individuals' development of affirmative perception of social justice and/or attitudes toward inclusive education. Finally, as the importance of data-based decision making and evidence-based practices is expanding, developing means of better measuring this important element of teacher quality both quantitatively and qualitatively is of utmost importance to teacher education programs. Continuing this type of research can contribute significantly to both screening and developmental assessment practices.

\section{References}

1. Shyman E (2013) Toward a globally sensitive definition of inclusive education based in social justice. International Journal of Development Disability and Education 62(4): 351-362.

2. Convention on the Rights of Persons with Disabilities (CRPD). Division for social policy and development disability.

3. Ware LP (2002) A moral conversation on disability: Risking the personal in educational contexts. Hypatia 17(3): 143-172.
4. Campbell E (2008) The ethics of teaching as a moral profession. Curriculum Inquiry 38(4): 357-385.

5. Sockett H (2009) Dispositions as virtues: The complexity of the construct. Journal of Teacher Education 60(3): 291-303.

6. Shyman E (2013) Beyond equality in the American classroom: The case for inclusive education. Lexington Books, Lanham, USA.

7. Singh DK, Stoloff DL (2008) Assessment of teacher dispositions. College Student Journal 42(4): 1169-1181.

8. Wilczenski FL (1995) Development of a scale to measure attitudes toward inclusive education. Educational and Psychological Measurement 55(2): 291-299.

9. Loreman T, Forlin C, Sharma U (2007) An international comparison of pre-service teacher attitudes towards inclusive education. Disability Studies Quarterly 27(4).

10. Wilczenski FL (1992) Measuring attitudes toward inclusive education. Psychology in the Schools 29(4): 306-312.

11. Cameron DL, Cook BG (2007) Attitudes of preservice teachers enrolled in an infusion preparation program regarding planning and accommodations for included students with mental retardation. Education and Training in Developmental Disabilities 42(3): 353-363.

12. Hwang YS, Evans D (2011) Attitudes toward inclusion: Gaps between beliefs and practice. International Journal of Special Education 26(1): 136-146.

13. Shippen ME, Crites SA, Houchins DE, Ramsey ML, Simon M (2005) Pre service teachers' perceptions of including students with disabilities. Teacher Education and Special Education 28(2): 92-99.

\section{Your next submission with Juniper Publishers will reach you the below assets}

- Quality Editorial service

- Swift Peer Review

- Reprints availability

- E-prints Service

- Manuscript Podcast for convenient understanding

- Global attainment for your research

- Manuscript accessibility in different formats

( Pdf, E-pub, Full Text, Audio)

- Unceasing customer service

Track the below URL for one-step submission https://juniperpublishers.com/online-submission.php 